\title{
Pharmacotherapy for anxiety disorders: drugs available
}

\author{
P. J. Cowen
}

The human search for tranquillity has embraced the use of numerous substances of which alcohol is probably the most widely used. Alcohol acts in part by facilitating neurotransmission at $\gamma$ aminobutyric acid (GABA) synapses and until recently the pharmacological treatment of anxiety was based principally on drugs that produce similar actions on this neurotransmitter and its receptor complex (Cowen \& Nutt, 1982) (Box 1).

Recent advances in the pharmacological management of clinical anxiety disorders reflect two main developments. First, there is now a better clinical delineation of the various anxiety syndromes, together with the recognition that certain drugs are efficacious in some disorders but not others. Buspirone, for example, is effective in generalised anxiety disorder (GAD) but not in panic disorder (Sheehan et al, 1993). Second, it is clear that several classes of antidepressant drugs produce benefit in a range of anxiety disorders even in the absence of significant depressive symptomatology (Box 2). This provides a much wider range of drug treatment options than was previously available (Table 1). In

\section{Box 1. Drugs that facilitate GABA neuro- transmission}

Alcohol

Barbiturates

Benzodiazepines

Chloral hydrate

Chlormethiazole

Meprobamate

Zopiclone

Zolpidem

\section{Table 1. Anxiolytic drugs: spectrum of activity}

\begin{tabular}{|c|c|c|c|}
\hline Drug & GAD & $\begin{array}{l}\text { Panic } \\
\text { disorder }^{1}\end{array}$ & $\begin{array}{l}\text { Social } \\
\text { phobia }\end{array}$ \\
\hline Benzodiazepines & + & $t^{2}$ & $?^{2}$ \\
\hline Buspirone & + & - & $?$ \\
\hline TCAs & + & + & - \\
\hline SSRIs & $?$ & + & + \\
\hline MAOIs & $?$ & + & + \\
\hline$\beta$-blockers & ? & - & - \\
\hline
\end{tabular}

general, drug treatment is used when anxiety causes significant functional impairment and appropriate psychological techniques are ineffective or cannot be properly instituted because of the degree of anxiety. There is some literature to suggest that the provision of psychological treatment may lessen the risk of relapse when drug treatment is discontinued.

\section{Benzodiazepines}

\section{Pharmacology}

Of the drugs that enhance GABA neurotransmission, only benzodiazepines will be considered here. Barbiturates are considered obsolete for the treatment of anxiety, and chlormethiazole, zopiclone and zolpidem are not licensed for such treatment .

Benzodiazepines facilitate GABA neurotransmission by binding to a specific receptor which exists

Dr Cowen is an MRC Clinical Scientist and Honorary Consultant Psychiatrist at Littlemore Hospital, Oxford OX4 4XN. After qualifying in medicine at University College Hospital and training in psychiatry at King's College Hospital, he studied psychopharmacology at the MRC Unit of Clinical Pharmacology in Oxford. He is particularly interested in the biochemistry and drug treatment of mood disorders. 
Box 2. In treating panic disorder bear in mind that antidepressant drugs:

Are as effective as benzodiazepines, are less likely to cause dependence, but have a slower onset of action

Require careful dose titration early in treatment to avoid jitteriness and high drop-out rates

Different classes are effective (TCAs, SSRIs and MAOIs), so that individual patients may be offered the drug likely to have the most acceptable side-effect profile

in a complex with post-synaptic GABA receptors. It is uncertain whether there is an endogenous ligand for the benzodiazepine receptor and, if so, whether it is anxiogenic or anxiolytic. GABA produces its pharmacological effects by increasing conductance through chloride channels. Benzodiazepines are allosteric modulators of this process, which means that while they enhance the effect of GABA they do not affect chloride conductance directly. This accounts for their safety relative to barbiturates.

\section{Clinical use}

There are many benzodiazepines available for clinical use but the main distinction of clinical value is the half-life and potency at the benzodiazepine receptor (Table 2). Generally, drugs with high potency at the receptor and short half-lives are more likely to cause withdrawal problems; they are therefore best avoided in the treatment of anxiety. Typically, benzodiazepines act fairly rapidly in anxiety disorders, particularly compared with agents that act primarily on monoamine function (see below).

Benzodiazepines are of established efficacy in the treatment of GAD, for which a drug such as diazepam is suitable. Diazepam is rapidly absorbed and can be used for continuous dosing or on an asrequired basis. If benzodiazepines are used to treat panic disorder (with or without agoraphobia), it is generally necessary to use a high-potency agent such as alprazolam or clonazepam. Such drugs ameliorate symptoms of panic more rapidly than tricyclic antidepressants (TCAs) and their efficacy appears to be maintained over several months. Furthermore, benzodiazepine treatment may be better tolerated than a TCA in panic disorder (Schweizer et al, 1993). There are limited data suggesting that clonazepam is effective in the treatment of social phobia, although findings with alprazolam have been more equivocal (Marshall et al, 1994).
Table 2. Comparison of some benzodiazepines

(from Bezchlibnyk-Butler \& Jeffries, 1995)

\begin{tabular}{|c|c|c|}
\hline Drug & $\begin{array}{l}\text { Comparative } \\
\text { dose }(\mathrm{mg})\end{array}$ & $\begin{array}{l}\text { Half-life of } \\
\text { parent compound } \\
\text { (hours) }\end{array}$ \\
\hline Diazepam & 5 & $14-17^{1}$ \\
\hline Temazepam & 10 & $3-25$ \\
\hline Lorazepam & 1 & $8-24$ \\
\hline Alprazolam & 0.5 & $9-20^{1}$ \\
\hline Clonazepam & 0.25 & $19-60$ \\
\hline
\end{tabular}

1. Vitisemetabulitenestend halt-lite

\section{Unwanted effects}

Despite the undoubted efficacy of benzodiazepines in the management of anxiety disorders, their use is attended by serious drawbacks. During treatment, sedation, cognitive impairment and ataxia may be problematic. Drug discontinuation, even with a slow taper, can cause troublesome withdrawal reactions and rebound anxiety, which may necessitate restarting treatment. This seems particularly apparent in the use of high-potency benzodiazepines for panic disorder, where withdrawal is often attended by the re-institution of panic attacks (Rickels et al, 1993a). Some patients, particularly those with a history of aggression, may be disinhibited by benzodiazepines.

\section{Drug interactions}

Benzodiazepines can potentiate the sedative effects of alcohol and other centrally-acting drugs. Respiratory depression has been reported in some patients receiving benzodiazepines with clozapine.

\section{Buspirone}

\section{Pharmacology}

Buspirone is an azapirone derivative which acts as an agonist at type $1 \mathrm{~A}$ serotonin $\left(5-\mathrm{HT}_{1 \mathrm{~A}}\right)$ receptors. The anxiolytic effect of buspirone has been proposed to result from stimulation of inhibitory $5-\mathrm{HT}_{1 \mathrm{~A}}$ receptors on 5-HT cell bodies, an action which decreases 5-HT cell firing and the release of 5-HT in terminal regions (Yocca et al, 1990). Animal studies indicate that this action, however, occurs fairly rapidly, whereas the clinical anxiolytic effect of buspirone can take weeks to manifest. Interestingly, repeated buspirone treatment may desensitise 
inhibitory 5- $\mathrm{HT}_{1 \mathrm{~A}}$ receptors and this, together with its modest post-synaptic $5-\mathrm{HT}_{1 \mathrm{~A}}$ receptor agonist actions, could lead to an overall increase in 5-HT neurotransmission. This model would be compatible with the anxiolytic effects of selective serotonin reuptake inhibitors (SSRIs), which also increase 5-HT neurotransmission (see below).

\section{Clinical use}

Buspirone is effective in the treatment of GAD but does not produce useful effects in panic disorder (Ortiz et al, 1987; Sheehan et al, 1993). It may have some modest effect in social phobia (Marshall et al, 1994). In contrast to benzodiazepines, buspirone needs to be administered for several days or weeks before a useful anxiolytic effect is obtained. It is not generally helpful in ameliorating benzodiazepine withdrawal and patients who have undergone previous benzodiazepine treatment may not respond well (Lader, 1991).

\section{Unwanted effects and interactions}

Unlike benzodiazepines, buspirone does not cause sedation and produces relatively little cognitive impairment at clinical doses. Also, there is little evidence that buspirone causes dependence or tolerance. Withdrawal reactions are not usually problematic (Lader, 1991). The use of buspirone is, however, associated with nausea, dizziness and headache. It should not be given with monoamine oxidase inhibitors (MAOIs) because the combination may lead to elevated blood pressure. This may be a consequence of the buspirone metabolite, 1-(2-pyrimidinyl)piperazine, an $\alpha_{2}$-adrenoceptor antagonist, which may facilitate noradrenaline release.

\section{TCAs}

\section{Pharmacology}

Tricyclic antidepressants are effective inhibitors of noradrenaline reuptake, and the tertiary derivatives, for example, amitriptyline, imipramine and, particularly, clomipramine, also block the reuptake of serotonin. In addition, TCAs block certain postsynaptic neurotransmitter receptors, which accounts for many of their side-effects (Table 3). The anxiolytic effects of TCAs, like their antidepressant effects, are often delayed for a number of weeks.

\section{Clinical use}

The primary indication for TCAs is the treatment of major depression. However, placebo-controlled studies have shown that imipramine (at about $150 \mathrm{mg}$ daily) is effective in GAD even in the absence of significant depressive symptomatology (Kahn et al, 1986; Rickels et al, 1993b). However, the time-course of its action differs from that of benzodiazepines. For example, Rickelset al (1993b) found that the anxiolytic effect of imipramine appeared somewhat slowly, with significant benefit over placebo becoming apparent only during the third week of treatment. In contrast diazepam was already more effective than placebo at the end of the first treatment week. Nevertheless, by the eighth week of treatment the anxiolytic effect of imipramine was greater than that of diazepam.

It is well established that imipramine is also effective in the treatment of panic disorder (with or without agoraphobia; Lydiard \& Ballenger, 1987). The optimum dosage is probably a little over $2 \mathrm{mg} / \mathrm{kg}$ (Mavissakalian \& Perel, 1995). As in the treatment of GAD, the effect of imipramine in panic and phobic avoidance appears relatively slowly and there may be significant drop-out rates early in treatment through worsening anxiety and 'jitteriness'. These problems can be minimised by slow escalation of the dosage (for example, increments of $10 \mathrm{mg}$ every 3-4 days; Clark et al, 1994). In contrast to their efficacy in GAD and panic disorder, studies of TCAs in social phobia have been disappointing (Marshall et al, 1994).

Imipramine has been the most widely studied TCA in controlled trials of anxiety disorders. However, amitriptyline and clomipramine are also effective in panic disorder and the latter drug may, in fact, be more effective than imipramine (Modigh et al, 1992). Clomipramine is a particularly potent inhibitor of serotonin reuptake and its efficacy in panic is of interest in view of the fact that the selective noradrenaline reuptake inhibitor, maprotiline, does not appear to possess significant anti-panic properties (Den Boer \& Westenberg, 1988). This suggests that potent serotonin reuptake inhibitors may have superior efficacy in the treatment of panic disorder, but whether this extends to GAD is not known.

\section{Unwanted effects}

The most serious potential problem of TCAs is cardiotoxicity through deliberate overdose. The risk of overdose is generally less in anxiety disorders than major depression, but suicidal behaviour in panic disorder is not uncommon (Appleby, 1994). Possibly agitation and jitteriness early in treatment could predispose to this kind of behaviour (Power \& Cowen, 1992), showing the importance of careful 
Pharmacological action

Muscarinic receptor blockade (anticholinergic)

$\alpha_{1}$-adrenoceptor blockade

Histamine $\mathrm{H}_{1}$-receptor blockade

Membrane stabilising properties
Adverse effect

Dry mouth, tachycardia, blurred vision, glaucoma, constipation, urinary retention, sexual dysfunction, cognitive impairment

Drowsiness, postural hypotension, sexual dysfunction, cognitive impairment Drowsiness, weight gain

Cardiac conduction defects, cardiac arrhythmias, epileptic seizures attention to initial dosing schedules. Despite the superficial attraction of sedation in an anxious subject, most patients with anxiety disorders try hard to maintain their usual activities. In these circumstances, imipramine may be a better choice than amitriptyline. While TCAs are undoubtedly useful in anxiety disorders the gains made during treatment are not always maintained following drug discontinuation; where possible, drug therapy should be withdrawn slowly (Clark et al, 1994).

\section{Drug interactions}

The sedative effects of TCAs can be increased by other centrally acting drugs. Drugs with effects on cardiac conduction, including antihistamines such as astemizole and terfenadine, should be used cautiously with TCAs. Plasma levels of TCAs may be increased by phenothiazines, calcium channel blockers, disulfiram and cimetidine. TCAs can potentiate the effects of sympathomimetic agents.

\section{SSRIs}

\section{Pharmacology}

The acute pharmacological action of SSRIs is essentially confined to the blockade of serotonin reuptake. While this action manifests early during treatment, the anxiolytic effects of SSRIs take several weeks to develop fully. It has been proposed that this delay represents the time needed for $5-\mathrm{HT}_{1 \mathrm{~A}}$ inhibitory autoreceptors to desensitise (see Buspirone, above) because it is only when this has occurred that the ability of an SSRI to increase serotonin neurotransmission can be expressed fully.

\section{Clinical use}

Studies in major depression have shown that SSRIs produce good relief of associated anxiety symptoms
(Cohn \& Wilcox, 1992), although whether SSRIs are effective in GAD without significant depressive symptomatology is not established with certainty. It is worth noting here that the antidepressant drug trazodone appears more effective than placebo in GAD (Rickelset al, 1993b). However, while trazodone is purported to block serotonin reuptake, it is unlikely that this action occurs to a significant extent at clinical doses.

There are placebo-controlled trials to show that fluvoxamine and paroxetine are effective in panic disorder (Blacket al, 1993; Oehrberg et al, 1995). Open studies indicate that fluoxetine may also produce benefit. As with TCAs the onset of effect may be delayed for a number of weeks and gradual dose escalation is needed to avoid jitteriness early in treatment. Effective doses are similar to those used in major depression but may be at the higher end of the range. SSRIs may also be helpful in social phobia. There are open reports of benefit in this disorder with fluoxetine (Marshall et al, 1994), and in one placebocontrolled trial with fluvoxamine ( $150 \mathrm{mg}$ daily) half of the drug-treated subjects showed significant improvement on measures of social and anticipatory anxiety (van Vliet et al, 1994).

\section{Unwanted effects}

Sedation and anticholinergic effects are uncommon but gastrointestinal effects are often experienced. Insomnia, anxiety and jitteriness may occur early in treatment. Sexual dysfunction, particularly anorgasmia, can be a persistent problem. Rarer but important adverse effects include dystonic reactions, low sodium states, and seizures. As with TCAs, it is not clear how far gains made during treatment are maintained following treatment cessation. SSRIs should be withdrawn slowly to avoid discontinuation reactions (Young \& Cowen, 1994).

\section{Drug interactions}

SSRIs can potently inhibit hepatic metabolising enzymes and thus are prone to raise plasma levels of co-administered drugs (Taylor \& Lader, 1996). Sertraline and citalopram appear to cause fewer such 
problems but have been less studied in anxiety disorders. Important clinical interactions have been reported with SSRIs and warfarin, antipsychotic drugs, TCAs, carbamazepine, phenytoin, aminophylline, benzodiazepines and terfenadine (Taylor \& Lader, 1966). SSRIs should not be given with MAOIs because of the risk of a toxic serotonin syndrome. This reaction may occur with selective type $A$ inhibitors and type B inhibitors, as well as the nonselective agents.

\section{MAOIs}

\section{Pharmacology}

There are two forms of monoamine oxidase (type A and type B) in the brain, which are encoded by separate genes. In general, type A metabolises intraneuronal noradrenaline and serotonin, whereas dopamine and tyramine are metabolised by both type A and type B. Conventional MAOIs such as isocarboxazid, phenelzine and tranylcypromine irreversibly inhibit both types of the enzyme. This gives rise to serious reactions with tyramine-containing foodstuffs, requiring strict dietary precautions. In contrast, moclobemide is a selective and reversible inhibitor of monoamine oxidase type A only. This results in a lack of significant interactions with foodstuffs and a quick offset of action (Priest, 1990).

\section{Clinical use}

Soon after their introduction, it was recognised that MAOIs had anxiolytic properties in patients with phobic anxiety syndromes (Kelly et al, 1970). It is not established with certainty whether or not MAOIs are effective in GAD but it seems likely that they are. There is evidence from controlled trials that MAOIs are effective in both panic disorder and social phobia (Lydiard \& Ballenger, 1987; Liebowitz et al, 1992).

Because of the dangers of food and drug interactions, conventional MAOIs are used as second-line drugs when safer agents have proved ineffective. Moclobemide has definite safety advantages over the conventional MAOIs, but its efficacy in anxiety disorders has not been widely studied. There is, however, evidence that it is effective in social phobia. In a placebo-controlled study of 78 subjects with social phobia, Versiani et al (1992) found similar response rates at 16 weeks for moclobemide (87\%) and phenelzine $(91 \%)$ and both were significantly better than placebo (43\%). Phenelzine had a quicker onset of action but was less well tolerated.

\section{Unwanted effects}

Conventional MAOIs cause a number of side-effects including insomnia, dizziness and postural hypotension. Weight gain, oedema and sexual dysfunction can be problematic long-term effects. Moclobemide is better tolerated, but insomnia, headache and nausea can occur. There is a strong clinical impression that withdrawing conventional MAOIs often leads to relapse of anxiety symptoms.

\section{Drug interactions}

MAOIs can cause dangerous hypertensive reactions with sympathomimetics, L-dopa and opiate analgesics. A serotonin syndrome can be provoked if MAOIs are combined with SSRIs or clomipramine. MAOIs can potentiate the effects of anti-diabetic agents. Moclobemide should not be used with serotonergic antidepressants and caution is needed with opiates. The pressor effects of sympathomimetics may be enhanced by moclobemide.

\section{Other drugs}

Certain other drugs are sometimes used to treat anxiety symptoms. For example, $\beta$-adrenoceptor antagonists such as propranolol are often helpful in ameliorating the physical symptoms of performance anxiety in otherwise healthy subjects. Although it has been suggested that $\beta$-adrenoceptor antagonists may have a role in the treatment of social phobia, recent studies have been rather disappointing (Marshall et $a l, 1993)$. There is no systematic evidence that $\beta$-adrenoceptor antagonists are useful in the treatment of other anxiety disorders such as panic disorder (Hayes \& Schulz, 1987), although many patients receive them from general practitioners.

Antipsychotic drugs in low doses are also used to treat anxiety symptoms, often in patients who have comorbid disorders such as substance abuse or aggressive personality disorders. In this situation the use of antipsychotic drugs presumably reflects the wish to avoid the dependence-producing or disinhibiting effects of benzodiazepines. While shortterm benefit often seems to occur, this practice is not supported by many trial data. It does appear, however, that low doses of antipsychotic drugs such as haloperidol and trifluoperazine may decrease anxiety and tension in subjects with borderline personality disorder (Soloff et al, 1986). However, the risk of movement disorders is a disincentive to longterm use of antipsychotic drugs for these indications. 


\section{References}

Appleby, L. (1994) Panic and suicidal behaviour. British Journal of Psychiatry, 164, 719-721.

Bezchlibnyk-Butler, K. Z. \& Jeffries, J. J. (1995) Handbook of Psychotropic Drugs, pp. 67-71. Seattle, WA: Hogrefe \& Huber.

Black, D. W., Wesner, R., Bowers, W., et al (1993) A comparison of fluvoxamine, cognitive therapy, and placebo in the treatment of panic disorder. Archives of General Psychiatry, 50, 44-50.

Clark, D. M., Salkovskis, P. M., Hackmann, A., et al (1994) A comparison of cognitive therapy, applied relaxation and imipramine in the treatment of panic disorder. British Journal of Psychiatry, 164, 759-769.

Cohn, J. B. \& Wilcox, C. S. (1992) Paroxetine in major depression: a double-blind trial with imipramine and placebo. Journal of Clinical Psychiatry, 53 (suppl. 2), 52-56.

Cowen, P. J. \& Nutt, D. J. (1982) Abstinence symptoms after withdrawal of tranquillising drugs: is there a common neurochemical mechanism? Lancet, ii, 360-362.

Den Boer, J. A. \& Westenberg, H. G. M. (1988) Effect of a serotonin and noradrenaline uptake inhibitor in panic disorder: a doubleblind comparative study with fluvoxamine and maprotiline. International Clinical Psychopharmacology, 3, 59-74.

Hayes, P. E. \& Schulz, S. C. (1987) Beta-blockers in anxiety disorders. Journal of Affective Disorders, 13, 119-130.

Kahn, R. J., McNair, D. M., Lipman, R. S., et al (1986) Imipramine and chlordiazepoxide in depressive and anxiety disorders. Archives of General Psychiatry, 43, 79-85.

Kelly, D., Guirguis, W., Frommer, E., et al (1970) Treatment of phobic states with antidepressants. A retrospective study of 246 patients. British Journal of Psychiatry, 116, 387-398.

Lader, M. (1991) Can buspirone induce rebound, dependence or abuse? British Journal of Psychiatry, 159 (suppl. 12), 45-51.

Liebowitz, M. R., Schneier, F., Campeas, R., et al (1992) Phenelzine versus atenolol in social phobia: a placebo-controlled comparison. Archives of General Psychiatry, 49, 290-300.

Lydiard, R. B. \& Ballenger, J. C. (1987) Antidepressants in panic disorder and agoraphobia. Journal of Affective Disorders, 13, 153-168.

Marshall, R. D., Schneier, F. R., Fallon, B. A., et al (1994) Medication therapy for social phobia. Journal of Clinical Psychiatry, 55 (suppl. 6), 33-37.

Mavissakalian, M. R. \& Perel, J. M. (1995) Imipramine treatment of panic disorder with agoraphobia: dose ranging and plasma level-response relationships. American Journal of Psychiatry, 152, 673-682.

Modigh, K., Westberg, P. \& Eriksson, E. (1992) Superiority of clomipramine over imipramine in the treatment of panic disorder: a placebo-controlled trial. Journal of Clinical Psychopharmacology, 12, 251-261.

Oehrberg, S., Cristiansen, P. E., Behnke, K., et al (1995) Paroxetine in the treatment of panic disorder: a randomised, double-blind, placebo-controlled study. British Journal of Psychiatry, 167, 374-379.

Ortiz, A., Pohl, R. \& Gershon, S. (1987) Azaspirodecanediones in generalised anxiety disorder: buspirone. Journal of Affective Disorders, 13, 131-143.

Power, A. C. \& Cowen, P. J. (1992) Fluoxetine and suicidal behaviour. Some clinical and theoretical aspects of a controversy. British Journal of Psychiatry, 161, 735-741.

Priest, R. G. (1990) Moclobemide and the reversible inhibitors of monoamine oxidase antidepressants. Acta Psychiatrica Scandinavica, 360, 39-41.

Rickels, K., Schweizer, E., Weiss, S., et al (1993a) Maintenance drug treatment for panic disorder. 2: Short and long term outcome after drug taper. Archives of General Psychiatry, 50, 61-68.

-, Downing R., Schweizer, E., et al (1993b) Antidepressants for the treatment of generalised anxiety disorder: a placebocontrolled comparison of imipramine, trazodone and diazepam. Archives of General Psychiatry, 50, 884-895.

Schweizer, E., Rickels, K., Weiss, S., et al (1993) Maintenance drug treatment of panic disorder. 1: Results of a prospective, placebo-controlled comparison of alprazolam and imipramine. Archives of General Psychiatry, 50, 51-60.
Sheehan, D. V., Raj, A. B., Harnett-Sheehan, K., et al (1993) The relative efficacy of high-dose buspirone and alprazolam in the treatment of panic disorder: a double-blind placebocontrolled study. Acta Psychiatrica Scandinavica, 88, 1-11.

Soloff, P. H., George, A., Nathan, S., et al (1986) Progress in pharmacotherapy of borderline disorders. Archives of General Psychiatry, 43, 691-697.

Taylor, D. \& Lader, M. (1996) Cytochromes and psychotropic drug interactions. British Journal of Psychiatry, 168, 529-532.

van Vliet, I. M., Den Boer, J. A. \& Westenberg, H. G. M. (1994) Psychopharmacological treatment of social phobia: a double blind placebo controlled study with fluvoxamine. Psychopharmacology, 115, 128-134.

Versiani, M., Nardi, A. E. \& Mundim, F. D. (1992) Pharmacology of social phobia. A controlled study of moclobemide and phenelzine. British Journal of Psychiatry, 161, 353-360.

Yocca, F. D. (1990) Neurochemistry and neurophysiology of buspirone and gepirone: interactions of pre-synaptic and post-synaptic 5-HT $1 \mathrm{~A}$ receptors. Journal of Clinical Psychopharmacology, 10 (suppl. 3), 6S-12S.

Young, A. H. \& Cowen, P. J. (1995) Antidepressant drugs. In Side-Effects of Drugs Annual 18 (eds J. K. Aronson \& C. J. van Boxtel), pp. 14-24. Amsterdam: Elsevier.

\section{Multiple choice questions}

1. The following drugs potentiate GABA neurotransmission:
a clonazepam
b fluvoxamine
c zopiclone
d alcohol.

2. Tricyclic antidepressants are of proven benefit in: a generalised anxiety disorder

b social phobia

c panic disorder

d agoraphobia.

3. In treating panic disorder, benzodiazepines:

a act more quickly than TCAs

b have higher drop-out rates than TCAs

c can be discontinued without difficulty

d improve panic but not phobic avoidance.

4. Irreversible, non-selective MAOIs:

a are second-line drugs in panic disorder

b are effective in social phobia

c do not require a tyramine-free diet

$\mathrm{d}$ are as well tolerated as RIMAs.

MCQ answers

$\begin{array}{llllll}\text { 1 } & & \text { 2 } & & 3 & 4 \\ \text { a T } & \text { a } & \text { T } & \text { a } & \text { T } & \text { a } \\ \text { b F } & \text { b F } & \text { b F } & \text { b T } \\ \text { c T } & \text { c T } & \text { c F } & \text { c F } \\ \text { d T } & \text { d T } & \text { d F } & \text { d F }\end{array}$

